\title{
Ultrasensitive Electrical Detection of Hemagglutinin for Point-of-Care Detection of Influenza Virus Based on a CMP-NANA Probe and Top-Down Processed Silicon Nanowire Field-Effect Transistors
}

\author{
Mihee Uhm ${ }^{1}$, Jin-Moo Lee ${ }^{2}$, Jieun Lee ${ }^{1}$, Jung Han Lee ${ }^{3}$, Sungju Choi ${ }^{1}{ }^{1}$, Byung-Gook Park ${ }^{3}$, \\ Dong Myong Kim ${ }^{1}$, Sung-Jin Choi ${ }^{1}$, Hyun-Sun Mo ${ }^{1}$, Yong-Joo Jeong ${ }^{2, * \mathbb{D}}$ and Dae Hwan Kim ${ }^{1, * \mathbb{D}}$ \\ 1 School of Electrical Engineering, Kookmin University, Seoul 02707, Korea; iljss88@naver.com (M.U.); \\ taiji11jieun@kookmin.ac.kr (J.L.); sungjuchoi@kookmin.ac.kr (S.C.); dmkim@kookmin.ac.kr (D.M.K.); \\ sjchoiee@kookmin.ac.kr (S.-J.C.); tyche@kookmin.ac.kr (H.-S.M.) \\ 2 School of Applied Chemistry, Kookmin University, Seoul 02707, Korea; elzem@kookmin.ac.kr \\ 3 School of Electrical and Computer Engineering, University of Seoul, Seoul 02504, Korea; \\ kusa159@snu.ac.kr (J.H.L.); bgpark@snu.ac.kr (B.-G.P.) \\ * Correspondence: jeongyj@kookmin.ac.kr (Y.-J.J.); drlife@kookmin.ac.kr (D.H.K.)
}

Received: 16 September 2019; Accepted: 15 October 2019; Published: 17 October 2019

\begin{abstract}
Rather than the internal genome nucleic acids, the biomolecules on the surface of the influenza virus itself should be detected for a more exact and rapid point-of-care yes/no decision for influenza virus-induced infectious diseases. This work demonstrates the ultrasensitive electrical detection of the HA1 domain of hemagglutinin (HA), a representative viral surface protein of the influenza virus, using the top-down complementary metal oxide semiconductor (CMOS) processed silicon nanowire (SiNW) field-effect transistor (FET) configuration. Cytidine-5'-monophospho-N-acetylneuraminic acid (CMP-NANA) was employed as a probe that specifically binds both to the aldehyde self-aligned monolayer on the SiNWs and to HA1 simultaneously. CMP-NANA was serially combined with two kinds of linkers, namely 3-aminopropyltriethoxysilane and glutaraldehyde. The surface functionalization used was verified using the purification of glutathione S-transferase-tagged HA1, contact angle measurement, enzyme-linked immunosorbent assay test, and isoelectric focusing analysis. The proposed functionalized SiNW FET showed high sensitivities of the threshold voltage shift $\left(\Delta \mathrm{V}_{\mathrm{T}}\right) \sim 51 \mathrm{mV} / \mathrm{pH}$ and the $\Delta \mathrm{V}_{\mathrm{T}}=112 \mathrm{mV}(63 \mathrm{mV} /$ decade $)$ with an ultralow detectable range of $1 \mathrm{fM}$ of target protein HA1.
\end{abstract}

Keywords: influenza virus; HA1; hemagglutinin; silicon nanowire biosensor; label-free; point-of-care

\section{Introduction}

Swine flu (H1N1), which is swan-originated and occurred in Mexico in 2009, has caused more than 17,000 cumulative deaths worldwide [1]. Adequate and convenient diagnostic tools for the rapid and accurate detection of the influenza virus from infected carriers are indispensable in controlling the wide spread of the virus at an early stage of its outbreak. However, the previously established and widely used methods for virus detection, such as enzyme-linked immunosorbent assay (ELISA) [2-6], polymerase chain reaction (PCR) [6-9], and fluorescence-based methods [6,10,11], immunoblotting [12], immunosensor-based methods [13], interferometry [14], fluoro-immunoassay [15,16], surface plasmon resonance-based methods [17], immunochromatography [18], gold-star optical methods [6], GOLD SIGN FLU [19], and rapid diagnostic tests with digital readout system [20], have been unable to satisfy these explosive demands because most of them cannot achieve a rapid $(<10$ s) detection 
and often require a relatively high level of sample manipulation that is inconvenient for infectious materials. Highly skilled personnel and expensive laboratory instruments are also required to perform these methods.

To overcome these limitations and challenging issues encountered by the previous methods, a few approaches for point-of-care (POC) tests that perform rapid and label-free electrical sensing of ions or biomolecules have been demonstrated. These tests are based on ion-sensitive field-effect transistors (FETs) configurations with silicon nanowires (SiNWs), carbon nanotubes, $\mathrm{AlGaN} / \mathrm{GaN}$ heterostructure, and $\mathrm{ZnO}$ nanotubes [21-28]. As is well known, FET-based electrical sensing biomolecules (including viruses) achieves faster detection than other methods [6]. Indeed, FET-based biomolecular sensors detect biomolecules within $10 \mathrm{~s}$ [26-28]. This detection time is two orders of magnitude smaller than the sensing time of RT-qPCR, the gold standard of biomolecular detection [29]. Moreover, the ion-sensitive FET (ISFET) array has been further industrialized as the extended-gate ISFET (EG-ISFET) [30-32].

However, the previous schemes of electrically sensing the influenza virus have a critical weakness. Figure 1a schematically illustrates the influenza virus structure. Figure $1 b, c$ show the two possible schemes of electrically sensing the influenza virus with the SiNWs. Note that the previous approaches tried to detect specific nucleic acid sequences (Figure $1 b$ ) rather than the virus particles themselves (Figure 1c) [6]. In fact, the nucleic acids exist not on the surface, but inside the virus particles as seen in Figure 1a. The electrical detection of nucleic acids as an indicator of a viral infection does not play a critical role as a potential POC platform to help a yes/no decision for infectious diseases in a doctor's clinic or at an airport because to extract nucleic acids as a virus infection marker, the specialized personnel needs to amplify specific nucleic acid sequences from the suspected patients' bodies. Furthermore, the influenza virus can live outside of the host cell as a virion, and it infects the host while floating in the air. It can survive even in objects touched or used by the infected patients. Although the survival time covers various ranges according to its surficial condition, it can nominally survive for approximately $5 \mathrm{~min}$ in the skin, $15 \mathrm{~min}$ in a dry paper tissue, and 1 or 2 days on a plastic surface. The virus can survive much longer if it exists in mucus $[33,34]$. Therefore, the biomolecules on the surface of the influenza virus itself, rather than the internal genome nucleic acids, should be paid very careful attention to determine a rapid and accurate method that would detect the influenza virus.

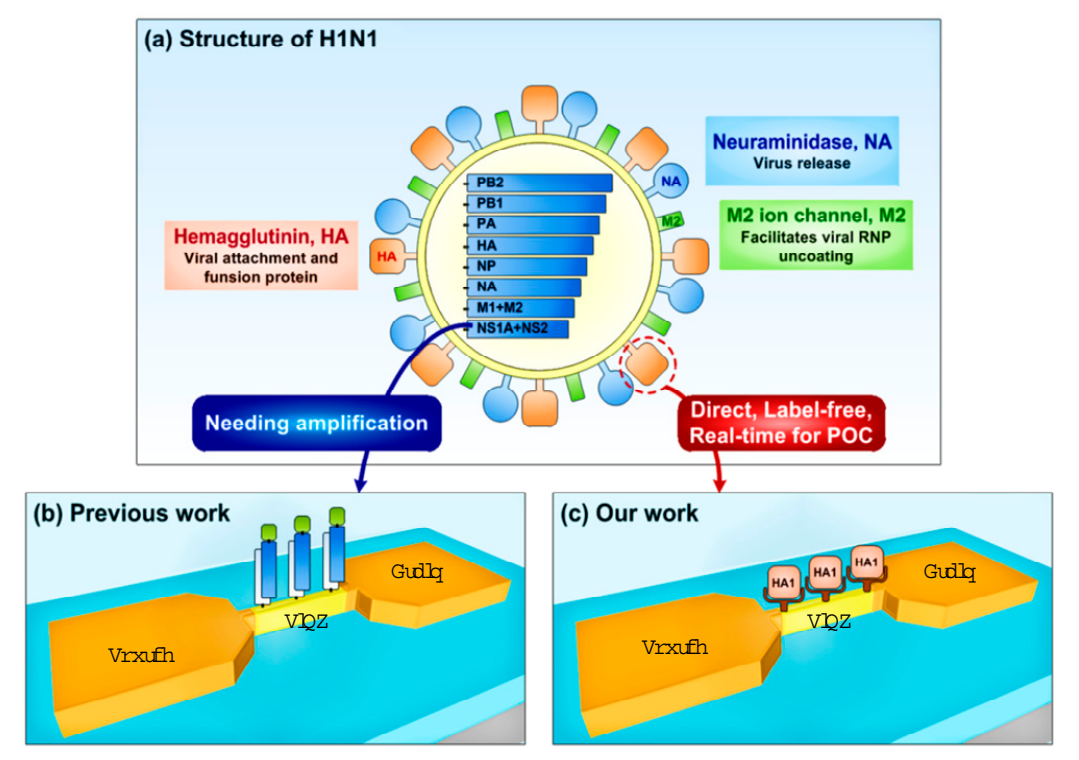

Figure 1. (a) Illustration of influenza virus structure. $(\mathbf{b}, \mathbf{c})$ Two schemes of electrical sensing of influenza virus with SiNWs; the detection of (b) specific nucleic acids sequences inside of influenza virus and (b) HA1 proteins on the surface of influenza virus itself that is involved in the initiation of infection.

The influenza virus generally drifts as a virion through the air until it infects a host. During the infection process, it secretes a viral surface protein called hemagglutinin (HA) (Figure 1a). The 
influenza HA protein determines the species that can be infected by a strain, and the binding location of the strain in the human respiratory tract [35]. In the strains that are easily transmitted among people, the HA proteins bind to receptors in the upper part of the respiratory tract, such as the nose, throat, and mouth. Thus, the detection of HAs involved in the initiation of infection will most efficiently and accurately recognize the existence of viruses in the human body. HA is an antigenic homotrimeric integral membrane glycoprotein. The HA monomer consists of a topped large HA1 globule and a long, helical chain anchored in the membrane by HA2 domains [36-39]. The HA1 domain contains sialic acid binding sites, and is well known to be essential for viral infection of host cells.

Inspired by these developments, we herein report the electrical and ultrahigh sensitive detection of HA1 using SiNW FETs fabricated by a complementary metal oxide semiconductor (CMOS)-compatible process. This is the first demonstration of electrical detection of the HA1 domain in HA, the viral surface protein of the influenza virus, using a top-down SiNW-based approach (Figure 1c). The surface functionalization with the effective probe and the intermediate linker, such as cytidine-5'-monophospho-N-acetylneuraminic acid (CMP-NANA) and glutaraldehyde (GA), and the high surface-to-volume ratio of the SiNWs revealed an ultrahigh sensitive detection (1 fM) of HA1 with a threshold voltage shift of $112 \mathrm{mV}(63 \mathrm{mV} / \mathrm{dec})$.

\section{Experimental Section}

\subsection{Purification of the GST-Tagged HA1 (HA1-GST)}

The HA1 domain of the influenza virus was prepared as a target biomolecule through the purification of glutathione S-transferase (GST)-tagged HA1 (i.e., HA1-GST). The genomic RNA of A/Korea/01/2009(H1N1) was provided by Korea Centers for Disease Control and Prevention (KCDC). The cDNAs were obtained by reverse transcription using a high-capacity RNA-to-cDNA kit (Applied Biosystems, USA). The HA1 gene was amplified by PCR using G-Taq DNA polymerase (Cosmogenetech, Korea) with the EcoRI forward primer (5'-GTGGTGGAATTCGACACATTATGTATAGGTTATCATGCG-3') and the XhoI reverse primer (5'-CATATTCTCGAGTCATCTAGATTGAATAGACGG-3'). The PCR product was gel-purified, digested with EcoRI/XhoI, and ligated with a similarly digested pGEX-4T-1 plasmid to make the expression vector, pGEX-4T-1/HA1. The HA1-GST protein expression plasmid, pGEX-4T-1/HA1, was transformed into E. coli Rosetta 2(DE3) ${ }^{\mathrm{TM}}$ competent cells. Ten liters of LB broth supplemented with ampicillin $(50 \mu \mathrm{g} / \mathrm{mL})$ was inoculated with the saturated pGEX-4T-1/HA1/Rosetta 2(DE3) ${ }^{\mathrm{TM}}$ culture (1/200 dilution) and grown at $37^{\circ} \mathrm{C}$ until $\mathrm{A}_{600}=0.8$. The HA1-GST protein expression was induced by the addition of IPTG $(0.5 \mathrm{mM})$. The cultures were then further incubated at $37^{\circ} \mathrm{C}$ for $4 \mathrm{~h}$. After cooling to $4{ }^{\circ} \mathrm{C}$, the cells were harvested by centrifugation and resuspended in a lysis buffer $(1 \times$ phosphate-buffered saline (PBS), $0.3 \mathrm{M} \mathrm{NaCl}, 1 \mathrm{mM}$ dithiothreitol (DTT), $1 \%$ Triton X-100). The cells were lysed by sonication (Sonosmasher, ULH-700s, microtip, 70\% power for $200 \mathrm{CNT}$ (10 s on, $20 \mathrm{~s}$ off) with ice cooling), and then centrifuged $(1 \mathrm{~h}, 13,000 \times g)$. The supernatant was filtered (Millipore syringe filter, $0.45 \mu \mathrm{m}$ ) and applied to $5 \mathrm{~mL}$ glutathione-agarose 4B (Incospharm, Korea) affinity column. The 5 $\mathrm{mL}$ column was washed with $50 \mathrm{~mL}$ washing buffer 1 (1× PBS, $1 \mathrm{mM}$ DTT, and $1 \%$ Triton X-100) and $50 \mathrm{~mL}$ of washing buffer $2(50 \mathrm{mM}$ Tris/ $\mathrm{Cl}(\mathrm{pH} 8.0)$ and $1 \mathrm{mM}$ DTT). The protein was then eluted with $10 \mathrm{~mL}$ elution buffer (50 mM Tris/Cl (pH 8.0), $1 \mathrm{mM}$ DTT, $0.1 \%$ Triton X-100, and $10 \mathrm{mM}$ glutathione). The purest fractions determined by $10 \%$ SDS-PAGE were combined and ultrafiltrated with an Amicon stirred cell (YM-30). During the ultrafiltration, desalting and buffer exchange were accompanied for the next column containing $180 \mathrm{~mL}$ of Sephadex G-100 resin (Sigma), which was previously washed with buffer 3 ( $25 \mathrm{mM}$ Tris- $\mathrm{HCl}(\mathrm{pH} 7.5)$, and $0.3 \mathrm{M} \mathrm{NaCl}$ ). After being applied to the Sephadex G-100 column, the protein sample $(\sim 5 \mathrm{~mL})$ was eluted with the same buffer at a flow rate of $0.3 \mathrm{~mL} / \mathrm{min}$. The purest fractions determined by $10 \%$ SDS-PAGE were combined, and the pooled fractions were ultrafiltrated with the Amicon stirred cell (YM-30). The purified protein in 30\% (v/v) glycerol was frozen at $-80^{\circ} \mathrm{C}$ for long-term storage. 
The HA1-GST protein concentration was determined by the absorbance measurement at $280 \mathrm{~nm}$ in $8 \mathrm{M}$ Urea (extinction coefficient: $96,720 \mathrm{M}^{-1} \mathrm{~cm}^{-1}$ ) as well as by using a Bio-Rad protein assay system (Bio-Rad) with bovine serum albumin as the standard. The HA1-GST protein was observed in a single band of $\sim 64 \mathrm{kDa}$ by $10 \%$ SDS-PAGE after staining with Coomassie Blue and Western blot (Figure 2a). Lane 1 shows the purified HA1-GST, while lane 2 shows the Western blot result of the purified HA1-GST. The gel was stained with Coomassie brilliant blue. The Western blotting band was detected with GST-antibody-HRP.

(a)

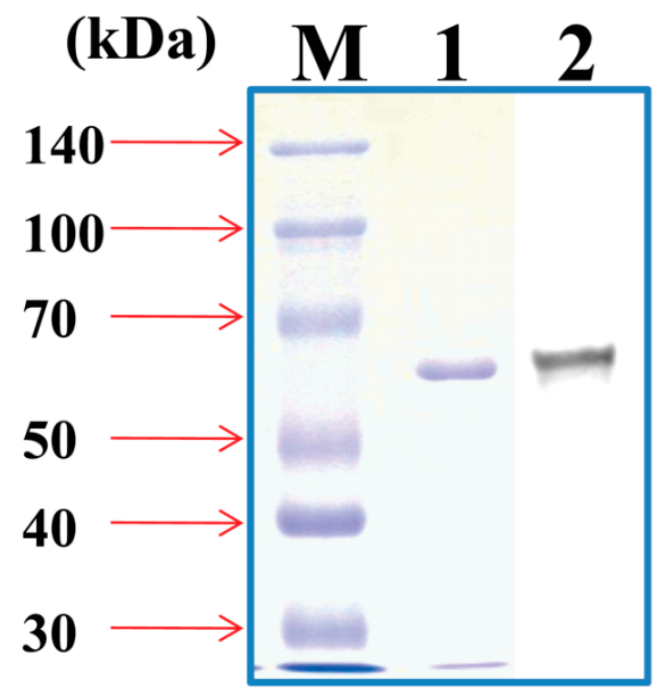

$10 \%$ SDS-PAGE analysis (b)

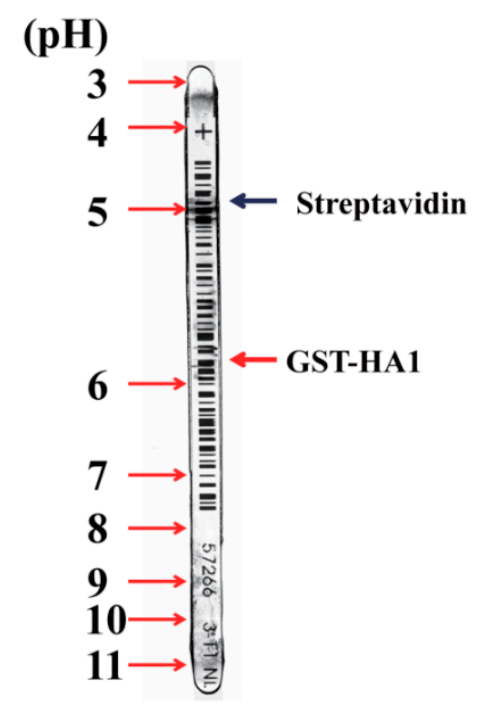

IEF analysis

Figure 2. The (a) SDS-PAGE and (b) IEF analysis results from the purification of GST-tagged HA1.

The isoelectric point (pI) of the purified protein was confirmed by the isoelectric focusing (IEF) analysis with the control protein, streptavidin (Figure $2 \mathrm{~b}$ ). Streptavidin showed $\mathrm{pI}=\sim 5$, while the purified HA1-GST showed $\mathrm{pI}=\sim 6$ in the IEF analysis of the purified HA1-GST.

\subsection{Fabrication and Electrical Characterization of the SiNW FETs}

The SiNW FETs were fabricated based on the top-down approach, which is advantageous compared to the bottom-up approach in terms of either the design of circuits and systems or the mass production because of its controllability and reproducibility, starting with boron doped at $4 \times 10^{15}$ $\mathrm{cm}^{-1} 6$ in. (100) silicon-on-insulator (SOI) wafers prepared through the implanted oxygen technique. The superficial $100 \mathrm{~nm}$ thick silicon was separated from the silicon substrate by $375 \mathrm{~nm}$ thick buried oxide (BOX). The SOI wafers were first dry-oxidized for $16 \mathrm{~min}$ at $950{ }^{\circ} \mathrm{C}$ to form $20 \mathrm{~nm}$ of buffer oxide as a protection layer for implantation. Consequently, the top Si layer thickness was thinned down to approximately $90 \mathrm{~nm}$. Next, the channel implantation was conducted with phosphorus ion (energy: $40 \mathrm{keV}$; dose: $3 \times 10^{13} \mathrm{~cm}^{-2}$ ) for the $n$-type accumulation mode device. After stripping the buffer oxide layer by the diluted HF solution, the annealing process was conducted at $950{ }^{\circ} \mathrm{C}$ for $30 \mathrm{~min}$ in a nitrogen environment (Figure $3 \mathrm{a}$ ). The active region of the device was patterned on the top Si layer by the mix-and-match process composed of e-beam lithography for defining the nanowire (length $L=$ $4 \mu \mathrm{m}$; width $W=70 \mathrm{~nm}$ ) and conventional photolithography for forming large silicon features like source and drain (Figure $3 b$ ). The SiNW and the source/drain were anisotropically etched with the $\mathrm{HBr} / \mathrm{O}_{2}$-based inductively coupled plasma by hydrogen silsesquioxane (HSQ) for e-beam lithography and a photoresist (PR) for photolithography as an etch mask (Figure 3c). A $10 \mathrm{~nm}$ thick oxide was thermally grown in a furnace for $42 \mathrm{~min}$ at $850{ }^{\circ} \mathrm{C}$ to form an implant slow down layer and reduce the 
size of the SiNW. An additional $10 \mathrm{~nm}$ thick oxide was then deposited for $14 \mathrm{~min}$ at $780{ }^{\circ} \mathrm{C}$ by means of a low-pressure chemical vapor deposition system (Figure 3d). Conventional photolithography was employed to form a photoresist mask that covered only the SiNW channel for the doping implantation of the source and drain $(\mathrm{S} / \mathrm{D})$ regions of the devices. The $\mathrm{S} / \mathrm{D}$ regions of the $n$-type accumulation-mode SiNW FETs were doped with arsenic at $50 \mathrm{keV}$ with a dose of $3 \times 10^{15} \mathrm{~cm}^{-\mathrm{c}}$. After the PR strip, the annealing step was followed at $1000{ }^{\circ} \mathrm{C}$ for $30 \mathrm{~min}$ in a nitrogen environment for the dopant activation (Figure 3e).

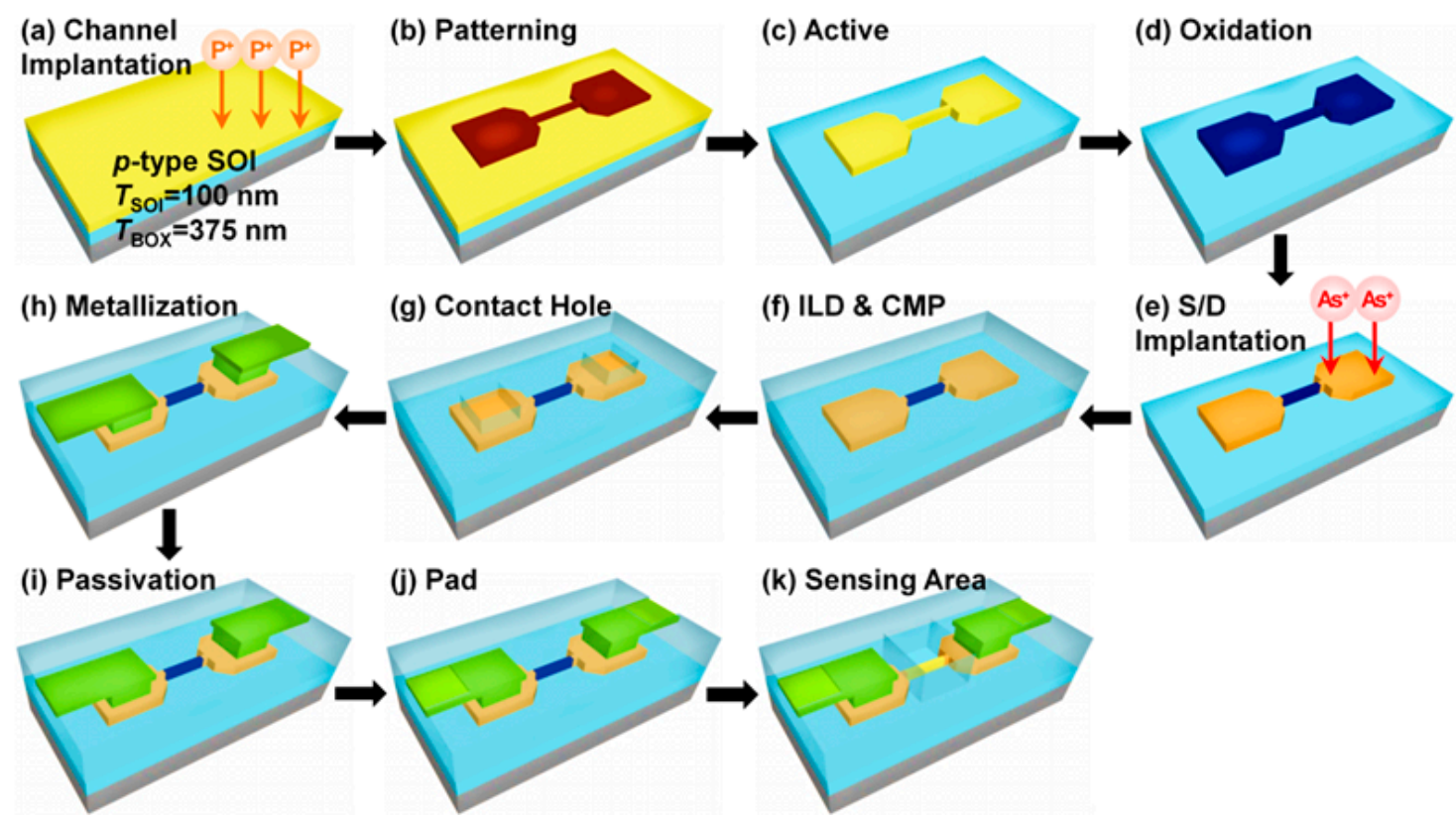

Figure 3. Schematic of the fabrication procedure for SiNW FET biosensors. A top-down approach was used to fabricate the SiNW FET-based influenza virus sensors.

Serial processes for the back-end-of-line fabrication of the SiNW FET sensor, which are compatible with the conventional CMOS process technology, were performed. A $50 \mathrm{~mm}$ thick oxide was deposited as an interlayer dielectric via high-density plasma chemical vapor deposition, followed by the planarization process through chemical mechanical planarization (CMP) (Figure 3f). After the CMP process, the contact etching was performed using a combination of photolithography and magnetic enhanced reactive ion etching (MERIE) in $\mathrm{CHF}_{3} / \mathrm{CF}_{4}$ plasma (Figure $3 \mathrm{~g}$ ). The formations of the metal interconnection line and the $\mathrm{Al}$ electrode were afterwards performed step-by-step using $\mathrm{Al}$ sputtering, photolithography, and MERIE in $\mathrm{BCl}_{2} / \mathrm{Cl}_{2}$ plasma (Figure 3h). Tetraethyl orthosilicate (TEOS) was deposited as the passivation oxide to protect the metal line and prevent the leakage current between the ionic buffer solution and the metal line during the biosensor operation in an aqueous environment (Figure 3i). The oxide layer on the metal pad region was etched by photolithography and MERIE in $\mathrm{CHF}_{3} / \mathrm{CF}_{4}$ plasma to measure the electrical characteristics of the fabricated devices on the 6 in. SOI wafer (Figure 3j).

The sensing area on the SiNW parts was opened by removing the TEOS passivation oxide via MERIE in $\mathrm{CHF}_{3} / \mathrm{CF}_{4}$ plasma. The biomolecule analyte in the aqueous environment can be detected by means of contacting the SiNW surface with the analyte through the removal of the oxide layer on the SiNW part. Finally, the alloy process was conducted to remove the dangling bonds and complete the whole process (Figure 3k).

Figure 4 shows the schematic view (Figure $4 a, b)$ and the scanning electron microscope (SEM) image (Figure 4c) of the fabricated SiNW FETs. The height, channel length, length of the open sensing area, and total length were $H=70 \mathrm{~nm}, L_{\text {open }}=2 \mu \mathrm{m}$, and $L_{\text {channel }}=1 \mu \mathrm{m}$, respectively. $L_{\text {channel }}$ depicts the separation between the S/D metallurgical junctions, and is effectively determined from $L_{\mathrm{open}}$ and 
two offsets of $0.5 \mu \mathrm{m}$ (Figure $4 \mathrm{~b}$ ). The SiNW width $W$ was varied from 30 to $400 \mathrm{~nm}$ through e-beam lithography. Figure $4 \mathrm{c}$ shows the case of $W=30 \mathrm{~nm}$.
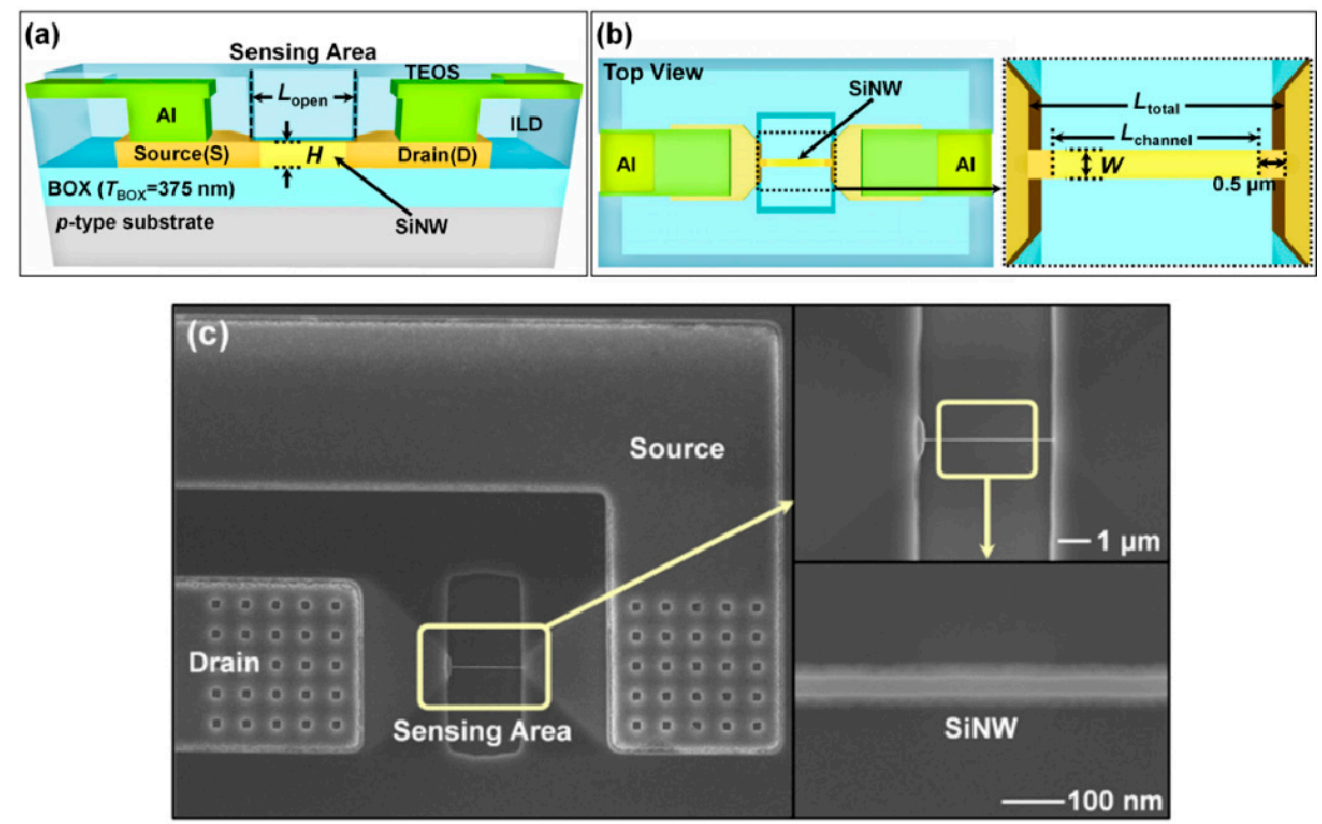

Figure 4. Schematics of (a) the cross section and (b) top view of SiNW FETs (not to scale). (c) SEM images of SiNW FET $\left(W=30 \mathrm{~nm}, H=70 \mathrm{~nm}, L_{\text {open }}=2 \mu \mathrm{m}\right.$, and $\left.L_{\text {channel }}=1 \mu \mathrm{m}\right)$.

As shown in Figure S1a,b in Supplementary Materials S1, a total of 11 masks were used in the wafer-scale process, and 83 SiNW FETs were integrated in each chip. The sensing area was located at the center of each chip, while 258 pads were located on the edge of each chip. The controllability of the width and the alignment of the individual SiNWs was verified by the SEM images of the fabricated SiNW FETs (Figure S1c in Supplementary Materials S1). Noticeably, 99\% of the integrated SiNWs on the 6 in. SOI wafer was built as the designed value. Therefore, the proposed top-down fabrication method is suitable for high-quality mass production, which is the definite and distinguished advantage of the top-down approach.

For the microfluidic channel measurement, a polydimethylsiloxane (PDMS) microfluidic channel (length $=4 \mathrm{~mm}$, width $=2.5 \mathrm{~mm}$, height $=200 \mu \mathrm{m}$ ) was constructed on a $9 \mathrm{~mm} \times 9 \mathrm{~mm}$ chip for the fluidic transport of the sample solution. The construction procedure is described in Figure S2 in Supplementary Materials S2. The electrical characterization for the HA1-GST detection based on the SiNW FETs was performed using the measurement setup presented in Figure S3 in Supplementary Materials S2. The electrical measurement was conducted using an HP4156C (Keysight, Santa Rosa, CA, USA) semiconductor parameter analyzer, which controls the liquid gate voltage $V_{\mathrm{LG}}$, drain voltage $V_{\mathrm{D}}$, and source voltage $V_{\mathrm{S}}$ after the flow of the electrolyte solution has been sufficiently stabilized.

\subsection{Surface Functionalization of the SiNWs}

For the HA1-GST detection with high sensitivity and selectivity, surface functionalization and immobilization were indispensable for the specific binding of HA1-GST to the SiNW surface in the SiNW FETs. The essence of our approach is to use CMP-NANA as a probe that specifically binds both to the aldehyde self-aligned monolayer (SAM) on the SiNWs and to HA1 simultaneously. We used two kinds of linkers (i.e., 3-aminopropyltriethoxysilane (APTES) and glutaraldehyde (GA)) and one probe (CMP-NANA) to bind the HA1-GST on the native oxide surface of the SiNW.

Figure 5 shows the scheme of the surface functionalization and immobilization of CMP-NANA and HA1 (left panel). First, after constructing the PDMS microfluidic channel, the device was treated by $\mathrm{UV}_{3}$ for $600 \mathrm{~s}$ to introduce more hydroxyl $(-\mathrm{OH})$ groups on the Si oxide surface, which is a 
well-known SAM method employing surface amine and aldehyde modification, and is for the specific binding of the amine group of CMP-NANA to SiNW [40]. APTES (first linker) and GA (second linker) were then sequentially applied and followed by the interaction with CMP-NANA. The device was functionalized by exposing the surface to 1\% APTES in 95\% ethanol for $1 \mathrm{~h}$ to form the SAM with the aldehyde group on the native oxide surface of the SiNWs. It was then washed with ethanol and dried with nitrogen and heated on a hot plate for $10 \mathrm{~min}$ at $120^{\circ} \mathrm{C}$. After the formation of the amine-terminated SAM by the preceding process, $2 \%$ GA in deionized water was coupled to the $\mathrm{NH}_{2}$ surface of the SiNW for $1 \mathrm{~h}$, followed by a thorough washing with deionized water. GA was chosen as the second linker because it has two aldehyde groups in its top and bottom; therefore, it can bind individually to all the amine groups of APTES and CMP-NANA (left panel, Figure 5).

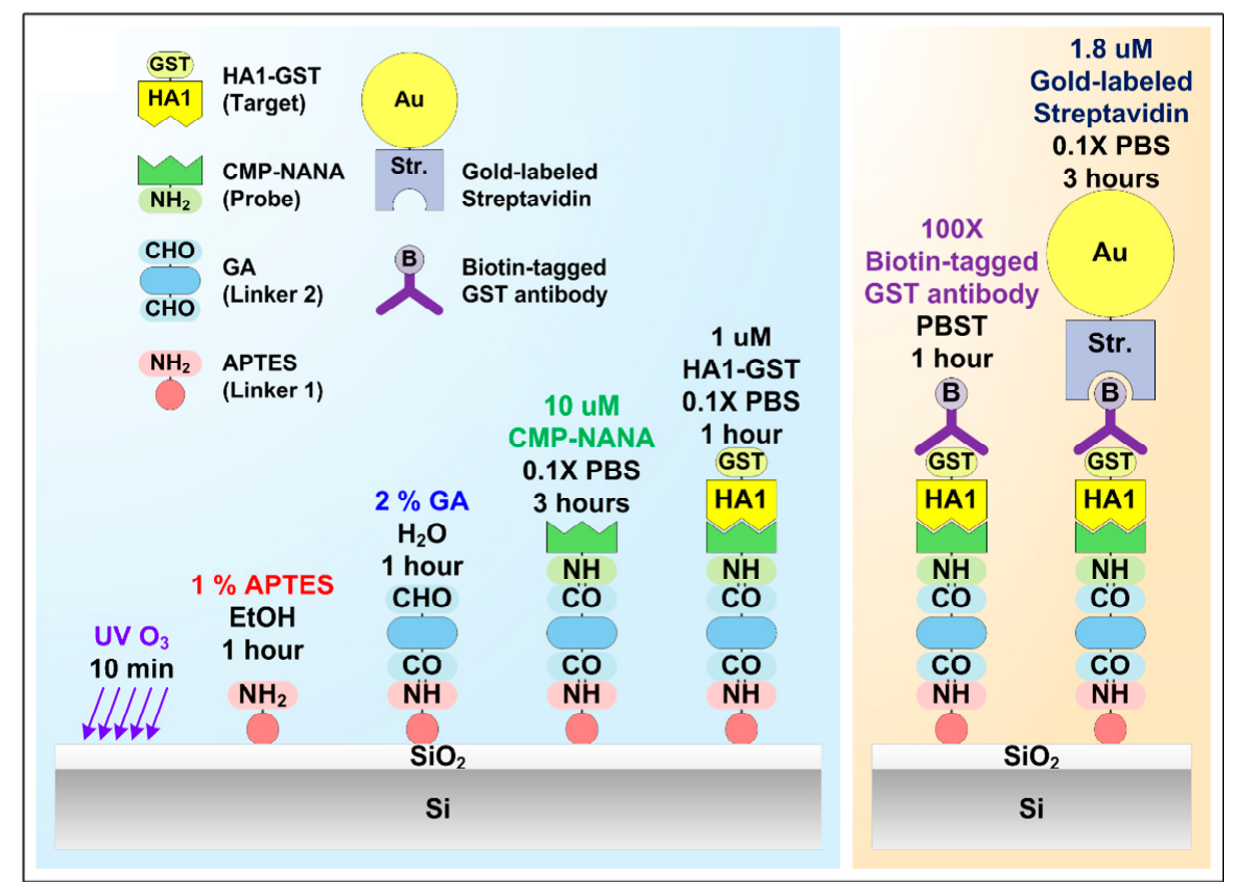

Figure 5. Scheme of the surface functionalization and immobilization of CMP-NANA and HA1 (left panel) and the preparation for tagging HA1 with gold nanoparticles for SEM analysis (right panel).

Subsequently, $10 \mu \mathrm{M}$ CMP-NANA in $0.1 \times$ PBS was added to the CHO surface to employ the sialic acid moiety as a probe for HA1. CMP-NANA was chosen as a critical probe in our case because it has both the sialic acid moiety and the amine $\left(-\mathrm{NH}_{2}\right)$ group. The former mimicked the process of a typical viral attachment to the cell surface that is activated by the binding of HA1 to the sialic acid group of the host cell surface. The latter provided the selected probe with the binding ability either to aldehyde $(-\mathrm{CHO})$ or carboxylic acid $(-\mathrm{COOH})$ that is widely available to the linker design for the specific binding of HA1 to the SiNW surface.

After excess material was removed by rinsing with $0.1 \times$ PBS, HA1-GST in $0.1 \times$ PBS was added to the surface for $40 \mathrm{~min}$. The sample was diluted with the same $0.1 \times$ PBS to verify the HA1 detection in the femtomolar concentration range.

The contact angle of each step was also observed during the surface modification processes, and the well-modified surface was confirmed. The contact angle of the bare Si wafer with native oxide was $49.8^{\circ}$ and changed into $72.4^{\circ}$ (after APTES functionalization), 67.8 (after APTES/GA functionalization), and $47.3^{\circ}$ (APTES/GA/CMP-NANA immobilization) (Figure 6). The changes in the contact angle indicated that the functional groups were adequately modified. We now finally confirmed the surface immobilization of CMP-NANA. 


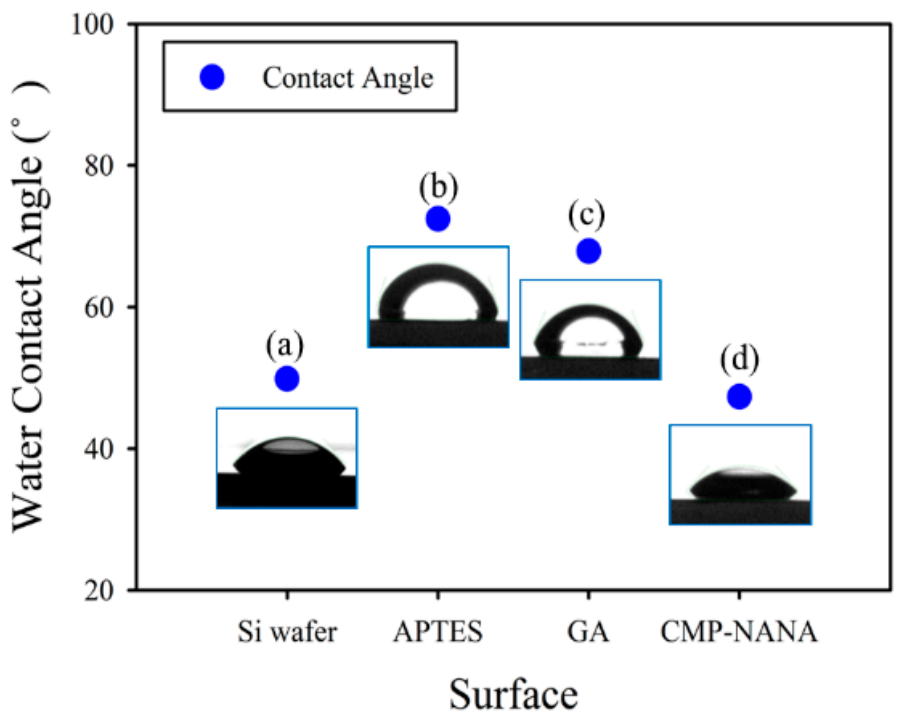

Figure 6. Water droplet contact angle measurements on four different functionalized Si wafer surfaces. (a) Bare Si wafer $\left(49.8^{\circ}\right)$, (b) APTES-functionalized surface $\left(72.4^{\circ}\right)$, (c) Glutaraldehyde-functionalized surface $\left(67.8^{\circ}\right)$, and (d) CMP-NANA immobilized surface $\left(47.3^{\circ}\right)$.

In addition, ELISA using GST-antibody-conjugated horseradish peroxidase (GST-antibody-HRP) was performed at each step of functionalization. The ELISA experiments were generally conducted to detect the protein-antibody interaction on the coated plate. We modified the conventional ELISA by performing on the Si wafer, by which we were able to determine whether or not the immobilized CMP-NANA on the surface binds to the HA1 domain. A $2 \times 2 \mathrm{~cm} \mathrm{Si} \mathrm{wafer} \mathrm{was} \mathrm{prepared,} \mathrm{and}$ CMP-NANA was immobilized on the Si wafer surface as described earlier. The immobilized surface was incubated with $5 \%(\mathrm{w} / \mathrm{v})$ bovine serum albumin in $1 \times$ PBST $(0.1 \%$ TWEEN-20 in PBS) solution for $1 \mathrm{~h}$ at room temperature to block the nonspecific binding, then rinsed with $1 \times$ PBST thrice. A $3 \mu \mathrm{M}$ HA1-GST protein was added to the surface-immobilized CMP-NANA for $1 \mathrm{~h}$ at room temperature, then rinsed with $1 \times$ PBST thrice. The GST-antibody-HRP (1:1000 in PBST, Santa Cruz, USA) was added to the bound HA1-GST for $1 \mathrm{~h}$ at room temperature. After which, the wafer was rinsed with $1 \times$ PBST thrice and dried in $\mathrm{N}_{2}$ gas. The surface was then immersed in $2 \mathrm{~mL} o$-phenylenediamine (OPD) solution to develop the color. Accordingly, $100 \mu \mathrm{L}$ of the solution was removed every $5 \mathrm{~min}$, and 100 $\mu \mathrm{L}$ of $2.5 \mathrm{~N} \mathrm{H}_{2} \mathrm{SO}_{4}$ was added to terminate the reaction. The absorbance was measured at $492 \mathrm{~nm}$ using a TRIAD microplate reader (Dynex Technologies, VA, USA).

Figure 7 clearly shows that the absorbance of the bare $\mathrm{Si}$, linkers (after APTES/GA functionalization), and sialic acid probe (after APTES/GA/ CMP-NANA immobilization) was low (0.04-0.05) at a $492 \mathrm{~nm}$ wavelength, whereas the absorbance signal of the sample employing the GST-antibody-HRP after the APTES/GA/CMP-NANA/ HA1-GST immobilization was much higher (1.2-1.3) within $10 \mathrm{~min}$. This result suggests that the HA1 specifically binds to the CMP-NANA immobilized on the SiNW surface. Thus, CMP-NANA and GA play the roles of a useful probe and an intermediate linker, respectively, for the specific binding of HA1 to the surface-modified SiNWs. 
(a)

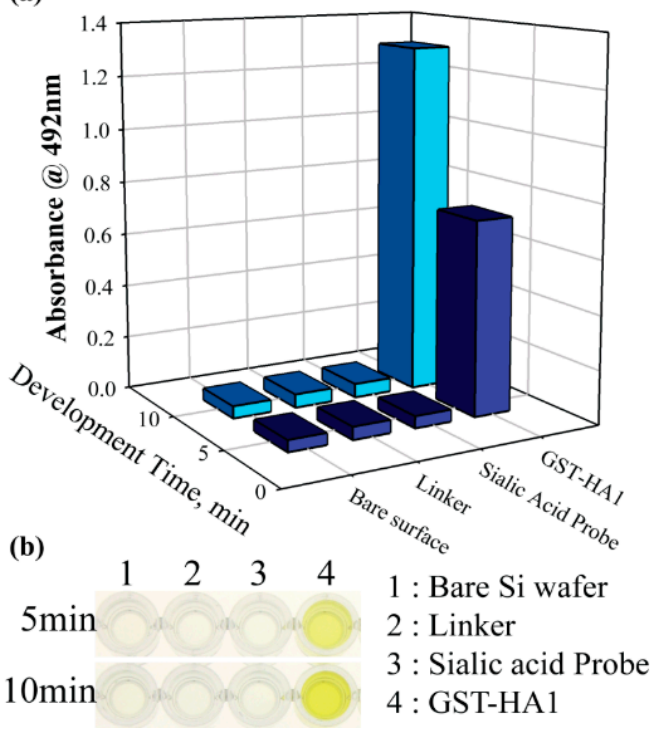

Figure 7. ELISA of functionalized Si wafer. (a) Absorbance was measured at $492 \mathrm{~nm}$ after sequential functionalization of Si wafer; bare surface, surface immobilized with linker (APTES and GA), surface functionalized with CMP-NANA, and addition of HA1 domain to the surface of functionalized CMP-NANA. (b) Color changes of terminated reaction with $2 \mathrm{~N} \mathrm{H}_{2} \mathrm{SO}_{4}$ in 96-well plate.

Furthermore, the SEM images were obtained to confirm that the change of the SiNW FET's electrical characteristics came from the bound HA1-GST on the SiNW surface. The right panel in Figure 5 shows the functionalization sequences to obtain the SEM images. Subsequently, 100x biotin-tagged GST-antibody (Santa Cruz, CA, USA) was reacted with the surface bound HA1-GST in $1 \times$ PBST solution for $1 \mathrm{~h}$ at room temperature, then rinsed with $1 \times$ PBST and dried with nitrogen thrice after the binding of the HA1-GST to the SiNW surface by a microfluidic channel and a syringe pump. A $1.8 \mu \mathrm{M}$ gold-labeled streptavidin (Sera care, Milford, MA, USA) was reacted with the biotin bound to the surface for $3 \mathrm{~h}$ at room temperature, then rinsed with $0.1 \times$ PBS and dried with nitrogen thrice.

Well-known strong bindings of the GST-GST antibody and biotin-streptavidin make it possible to confirm the successful immobilization of HA1 on SiNW by SEM analysis. Figure 8 shows the SEM image of SiNW after all treatments, in which many gold nanoparticles were observed to be located on and around SiNW. Thus, it was confirmed that the target protein HA1 was successfully immobilized on the SiNWs.

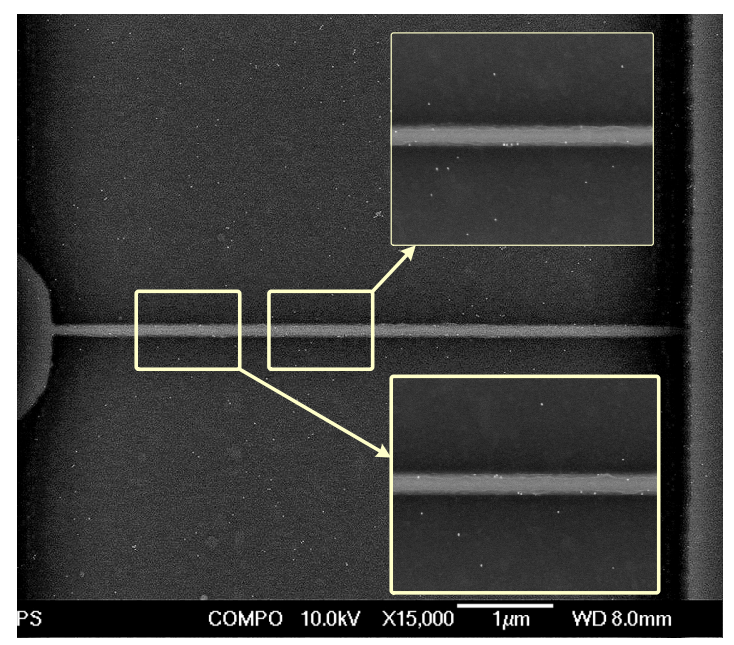

Figure 8. The SEM image of SiNW after the gold nanoparticle-tagging treatment to verify the immobilization of CMP-NANA and HA1. 


\section{Result and Discussion}

\section{1. $p H$ Sensing in the SiNW FET}

The $\mathrm{pH}$ sensing was performed to confirm a fundamental operation of the fabricated SiNW FETs. The SiNW FET surface was functionalized using APTES to obtain a surface with an amine $\left(-\mathrm{NH}_{2}\right)$. By using $0.1 \mathrm{M}$ potassium phosphate buffers ( $\mathrm{pH}$ 5-9) for the $\mathrm{pH}$ solutions, we eliminated the possible side effects caused by the alkali metal ions by maintaining a constant concentration of alkali metal ions. Therefore, our SiNWs could selectively respond to the presence of hydrogen ions.

Figure 9a shows the transfer characteristics of the n-type SiNW FETs with varying $\mathrm{pH}$ values, where $I_{\mathrm{DS}}$ denotes the drain-to-source current, and the drain-to-source voltage $\left(V_{\mathrm{DS}}\right)$ is fixed at $1 \mathrm{~V}$. The $-\mathrm{NH}_{2}$ group was protonated to $-\mathrm{NH}_{3}$ at a low $\mathrm{pH}$, resulting in a greater positive potential. In contrast, the $-\mathrm{SiOH}$ group was deprotonated to $-\mathrm{SiO}-$ at a high $\mathrm{pH}$, resulting in a greater negative potential. The surface potential at the $\mathrm{SiO}_{2} / \mathrm{SiNW}$ interface was confirmed to be well-modulated by the $\mathrm{pH}$ values. The average shift of the threshold voltage $V_{\mathrm{T}}\left(\Delta V_{\mathrm{T}}\right)$ by $\mathrm{pH}$ was $51 \mathrm{mV} / \mathrm{pH}$ (Figure $\left.9 \mathrm{~b}\right)$, which is comparable to the ideal Nernst limit $\left(\sim 59.2 \mathrm{mV} / \mathrm{pH}\right.$ at $\left.25^{\circ} \mathrm{C}\right)$.
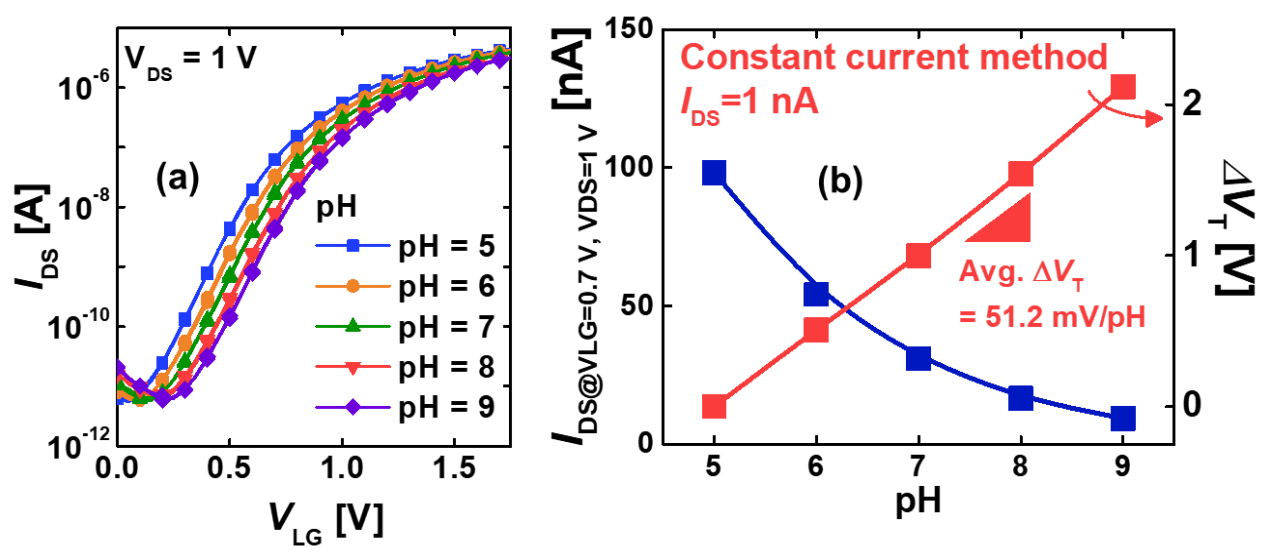

Figure 9. (a) Transfer characteristics of SiNW FETs with varying $\mathrm{pH}$ values. (b) the $\mathrm{pH}$-dependencies of the drain-to-source current $\left(I_{\mathrm{DS}}\right)$ and $\Delta V_{\mathrm{T}}$ in SiNW FETs. The sensitivity of $\Delta V_{\mathrm{T}}=51.2 \mathrm{mV} / \mathrm{pH}$ was comparable to the Nernst limit.

\subsection{Electrical Detection of HA1-GST}

The electrical detection of HA1-GST was conducted for the SiNW FETs after the APTES/GA/CMP-NANA/HA1-GST immobilization. The PBS solution was used as the background environment.

Figure 10a shows the measured transfer curves of the SiNWs with $W=70 \mathrm{~nm}$ at $V_{\mathrm{DS}}=0.1 \mathrm{~V}$ depending on the HA1-GST concentration ( $\left.n_{\text {HA1-GST }}\right)$. The case of $0 \mathrm{M}$ suggests the condition that only the PBS solution was flowing through the microfluidic channel. The transfer curve was clearly shifted to a positive $V_{\text {LG }}$ direction with the increase of the HA1-GST concentration. The observed shift was very consistent with the pI value $\sim 6$ of HA1-GST (Figure $2 b$ ) considering the $\mathrm{pH}$ value $=7.4$ of the PBS solution because the used SiNW operated in the $n$-type accumulation-mode FET. SiNW effectively felt a larger amount of negative charges and depleted more and more electrons as the HA1-GST concentration increased, resulting in the current decreasing and the FET threshold voltage increasing to a positive $V_{\text {LG }}$ direction. 

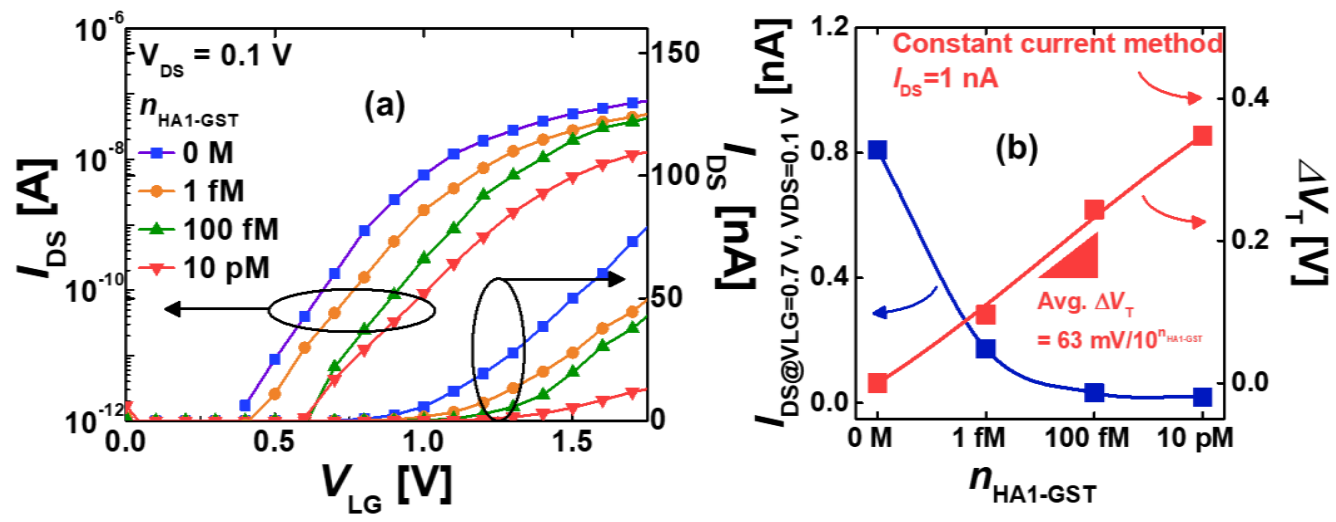

Figure 10. (a) Measured transfer curves of the SiNW FETs after APTES/GA/CMP-NANA/HA1-GST immobilization, depending on the concentration of HA1-GST. (b) Measured $I_{\mathrm{DS}}$ and $\Delta V_{\mathrm{T}}$ with various concentrations of HA1-GST.

The voltage-concentration plot in Figure 10b is highly linear, and the HA1-GST sensitivity was determined as $\Delta V_{\mathrm{T}}=63 \mathrm{mV} / \mathrm{dec}$. This reveals an ultralow detectable range $(1 \mathrm{fM})$ of the target protein HA1 by the fabricated SiNWs. Therefore, the CMP-NANA is verified to be a potentially useful probe for the virus protein and can play the role of ultrasensitive virus detection with the silica-binding surface (i.e., $\mathrm{Si}$ or $\mathrm{SiO}_{2}$ ) by combining APTES and GA linkers.

The previous Si FET-based HA detection [41] achieved $\Delta V_{\mathrm{T}}<100 \mathrm{mV}$ in the HA concentration range $10^{-18}-10^{-8} \mathrm{M}$, and $\Delta V_{\mathrm{T}}=\sim 20 \mathrm{mV}$ at $1 \mathrm{fM}$ HA. In this study, we achieved $\Delta V_{\mathrm{T}}=112 \mathrm{mV}$ at $1 \mathrm{fM}$ HA (Figure 10b). The noticeably higher sensitivity in our work is attributed to the combined use of CMP-NANA and SiNWs (high surface-to-volume ratio) and confirms the usefulness and appropriateness of immobilizing the SiNWs with CMP-NANA for the FET-based electrical detection of HA.

In addition, the signal-to-noise ratio (SNR) of our SiNW FETs, defined as SNR $=\Delta I / \delta I$, was evaluated as 3433 (where $\Delta I=35 \mathrm{pA}$ and $\delta I=103 \mathrm{nA}$ denote the measured current-signal response and the root-mean-squared current noise amplitude, respectively). Herein, $\Delta I$ was determined as the current change from $\mathrm{pH} 10$ to $\mathrm{pH} 4$, and $\delta I$ was obtained by integrating the current noise power spectral density ( $\mathrm{S}_{\mathrm{ID}}$ ) from $10 \mathrm{~Hz}$ to $1 \mathrm{kHz}$ and square-rooting the result. The $\mathrm{S}_{\mathrm{ID}}$ was taken from the low-frequency noise characteristics of our SiNW FETs. The observed SNR is comparable to [42] and will be improved and comprehensively characterized in further study.

\section{Conclusions}

In summary, we demonstrated herein the ultrasensitive electrical detection of the HA1 domain of HA, which is critically involved in influenza virus infection, by combining SiNW FETs and the functionalization scheme based on the CMP-NANA probe, GA, and APTES linkers. To the best of our knowledge, we provide the first demonstration of detecting not the specific nucleic acid sequences inside the influenza virus particles, but the viral surface protein on the influenza virus itself, by the top-down SiNW FET approach. Even femtomolar concentrations of HA1 can be detected $\left(\Delta V_{\mathrm{T}}=63\right.$ $\mathrm{mV} / \mathrm{dec}, \Delta V_{\mathrm{T}}=112 \mathrm{mV}$ at $1 \mathrm{fM}$ HA1) by virtue of the stable and efficient CMP-NANA probe and intermediate GA linker, and the high surface-to-volume ratio of the SiNWs. Furthermore, a good linearity and reasonable SNR were verified. The mass-producible functionalized SiNW-based sensor array can potentially realize fast, label-free, and exact POC yes/no diagnosis of the influenza virus.

Supplementary Materials: The following are available online at http://www.mdpi.com/1424-8220/19/20/4502/s1, Controllability of top-down processed SiNWs on the 6 in SOI wafer (S1) and Microfluidic Channel and Electrical Characterization of the SiNW FETs (S2).

Author Contributions: M.U. and J.-M.L. contributed equally to this work. Conceptualization, M.U., J.-M.L., J.L., J.H.L., Y.-J.J. and D.H.K.; Investigation, M.U., J.-M.L. and J.L.; Methodology, M.U., J.-M.L., J.L. and J.H.L.; 
Writing—original draft, M.U. and J.-M.L.; Writing—review \& editing, S.C., B.-G.P., D.M.K., S.-J.C., H.-S.M., Y.-J.J. and D.H.K..

Funding: This work was supported by the National Research Foundation of Korea (NRF) through the Korean Government (Ministry of Education, Science and Technology (MEST)) under grant number [2016R1A5A1012966], [2017R1A2B4006982], [18ZB1800], and [2016M3A7B4909668]. Y.-J Jeong was supported by a grant of the Korea Health Technology R\&D Project through the Korea Health Industry Development Institute (KHIDI), funded by the Ministry of Health \& Welfare, Republic of Korea under grant number [HI15C2917].

Acknowledgments: The CAD software was supported by SILVACO and IDEC.

Conflicts of Interest: The authors declare no conflict of interest.

\section{References}

1. Committee, E.; Committee, T.; Zealand, N. Media Centre H1N1 in Post-Pandemic Period. Available online: https:/www.who.int/mediacentre/news/statements/2010/h1n1_vpc_20100810/en/ (accessed on 16 October 2019).

2. He, Q.; Velumani, S.; Du, Q.; Lim, C.W.; Ng, F.K.; Donis, R.; Kwang, J. Detection of H5 Avian Influenza Viruses by Antigen-Capture Enzyme-Linked Immunosorbent Assay Using H5-Specific Monoclonal Antibody. Clin. Vaccine Immunol. 2007, 14, 617-623. [CrossRef] [PubMed]

3. Lee, B.W.; Bey, R.F.; Baarsch, M.J.; Simonson, R.R. ELISA Method for Detection of Influenza A Infection in Swine. J. Vet. Diagnostic Investig. 1993, 5, 510-515. [CrossRef] [PubMed]

4. Velumani, S.; Ho, H.-T.; He, F.; Musthaq, S.; Prabakaran, M.; Kwang, J. A Novel Peptide ELISA for Universal Detection of Antibodies to Human H5N1 Influenza Viruses. PLoS ONE 2011, 6, e20737. [CrossRef] [PubMed]

5. Watcharatanyatip, K.; Boonmoh, S.; Chaichoun, K.; Songserm, T.; Woratanti, M.; Dharakul, T. Multispecies detection of antibodies to influenza A viruses by a double-antigen sandwich ELISA. J. Virol. Methods 2010, 163, 238-243. [CrossRef] [PubMed]

6. Dziąbowska, K.; Czaczyk, E.; Nidzworski, D. Detection Methods of Human and Animal Influenza Virus-Current Trends. Biosensors 2018, 8, 94. [CrossRef] [PubMed]

7. Use of PCR-enzyme immunoassay for identification of influenza A virus matrix RNA in clinical samples negative for cultivable virus. J. Clin. Microbiol. 1994, 32, 623-628.

8. Poon, L.L.M.; Chan, K.H.; Smith, G.J.; Leung, C.S.W.; Guan, Y.; Yuen, K.Y.; Peiris, J.S.M. Molecular Detection of a Novel Human Influenza (H1N1) of Pandemic Potential by Conventional and Real-Time Quantitative RT-PCR Assays. Clin. Chem. 2009, 55, 1555-1558. [CrossRef]

9. Stone, B.; Burrows, J.; Schepetiuk, S.; Higgins, G.; Hampson, A.; Shaw, R.; Kok, T. Rapid detection and simultaneous subtype differentiation of influenza A viruses by real time PCR. J. Virol. Methods 2004, 117, 103-112. [CrossRef]

10. Martinez-Sobrido, L.; Cadagan, R.; Steel, J.; Basler, C.F.; Palese, P.; Moran, T.M.; Garcia-Sastre, A. Hemagglutinin-Pseudotyped Green Fluorescent Protein-Expressing Influenza Viruses for the Detection of Influenza Virus Neutralizing Antibodies. J. Virol. 2010, 84, 2157-2163. [CrossRef]

11. Munasinghe, V.R.N.; Corrie, J.E.T.; Kelly, G.; Martin, S.R. Fluorescent ligands for the hemagglutinin of influenza A: Synthesis and ligand binding assays. Bioconjug. Chem. 2007, 18, 231-237. [CrossRef]

12. Bahgat, M.M.; Kutkat, M.A.; Nasraa, M.H.; Mostafa, A.; Webby, R.; Bahgat, I.M.; Ali, M.A.A. Characterization of an avian influenza virus H5N1 Egyptian isolate. J. Virol. Methods 2009, 159, 244-250. [CrossRef] [PubMed]

13. Wang, R.; Wang, Y.; Lassiter, K.; Li, Y.; Hargis, B.; Tung, S.; Berghman, L.; Bottje, W. Interdigitated array microelectrode based impedance immunosensor for detection of avian influenza virus H5N1. Talanta 2009, 79, 159-164. [CrossRef] [PubMed]

14. Gopinath, S.C.B.; Awazu, K.; Tominaga, J.; Kumar, P.K.R. Monitoring biomolecular interactions on a digital versatile disk: A BioDVD platform technology. ACS Nano 2008, 2, 1885-1895. [CrossRef] [PubMed]

15. Payungporn, S.; Chutinimitkul, S.; Chaisingh, A.; Damrongwantanapokin, S.; Buranathai, C.; Amonsin, A.; Theamboonlers, A.; Poovorawan, Y. Single step multiplex real-time RT-PCR for H5N1 influenza A virus detection. J. Virol. Methods 2006, 131, 143-147. [CrossRef]

16. Chen, L.; Sheng, Z.; Zhang, A.; Guo, X.; Li, J.; Han, H.; Jin, M. Quantum-dots-based fluoroimmunoassay for the rapid and sensitive detection of avian influenza virus subtype H5N1. Luminescence 2010, 25, 419-423. [CrossRef] 
17. Gopinath, S.C.B.; Misono, T.S.; Kawasaki, K.; Mizuno, T.; Imai, M.; Odagiri, T.; Kumar, P.K.R. An RNA aptamer that distinguishes between closely related human influenza viruses and inhibits haemagglutinin-mediated membrane fusion. J. Gen. Virol. 2006, 87, 479-487. [CrossRef]

18. Watanabe, M.; Nakagawa, N.; Ito, M.; Ihara, T. Sensitivity of rapid immunoassay for influenza A and B in the early phase of the disease. Pediatr. Int. 2009, 51, 211-215. [CrossRef]

19. Akaishi, Y.; Matsumoto, T.; Harada, Y.; Hirayama, Y. Evaluation of the rapid influenza detection tests GOLD SIGN FLU and Quick Navi-Flu for the detection of influenza A and B virus antigens in adults during the influenza season. Int. J. Infect. Dis. 2016, 52, 55-58. [CrossRef]

20. Ryu, S.W.; Suh, I.B.; Ryu, S.M.; Shin, K.S.; Kim, H.S.; Kim, J.; Uh, Y.; Yoon, K.J.; Lee, J.H. Comparison of three rapid influenza diagnostic tests with digital readout systems and one conventional rapid influenza diagnostic test. J. Clin. Lab. Anal. 2018, 32, 1-7. [CrossRef]

21. Shao, Q.; Que, R.; Shao, M.; Zhou, Q.; Ma, D.D.D.; Lee, S.-T. Shape controlled flower-like silicon oxide nanowires and their $\mathrm{pH}$ response. Appl. Surf. Sci. 2011, 257, 5559-5562. [CrossRef]

22. Kim, W.; Javey, A.; Vermesh, O.; Wang, Q.; Li, Y.; Dai, H. Hysteresis Caused by Water Molecules in Carbon Nanotube Field-Effect Transistors. Nano Lett. 2003, 3, 193-198. [CrossRef]

23. Wang, L.; Bu, Y.; Li, L.; Ao, J.-P. Effect of thermal oxidation treatment on pH sensitivity of AlGaN/GaN heterostructure ion-sensitive field-effect transistors. Appl. Surf. Sci. 2017, 411, 144-148. [CrossRef]

24. Liu, L.; Shao, J.; Li, X.; Zhao, Q.; Nie, B.; Xu, C.; Ding, H. High performance flexible pH sensor based on carboxyl-functionalized and DEP aligned SWNTs. Appl. Surf. Sci. 2016, 386, 405-411. [CrossRef]

25. Kathiravan, D.; Huang, B.-R.; Saravanan, A.; Yeh, C.-J.; Leou, K.-C.; Lin, I.-N. Interfacial effects in ZnO nanotubes/needle-structured graphitic diamond nanohybrid for detecting dissolved acetone at room temperature. Appl. Surf. Sci. 2017, 426, 630-638. [CrossRef]

26. Kharitonov, A.B.; Shipway, A.N.; Willner, I. An Au Nanoparticle/Bisbipyridinium Cyclophane-Functionalized Ion-Sensitive Field-Effect Transistor for the Sensing of Adrenaline. Anal. Chem. 1999, 71, 5441-5443. [CrossRef] [PubMed]

27. Poghossian, A.; Schöning, M.J. Label-Free Sensing of Biomolecules with Field-Effect Devices for Clinical Applications. Electroanalysis 2014, 26, 1197-1213. [CrossRef]

28. Hai, W.; Goda, T.; Takeuchi, H.; Yamaoka, S.; Horiguchi, Y.; Matsumoto, A.; Miyahara, Y. Specific Recognition of Human Influenza Virus with PEDOT Bearing Sialic Acid-Terminated Trisaccharides. ACS Appl. Mater. Interfaces 2017, 9, 14162-14170. [CrossRef]

29. Shen, F.; Wang, J.; Xu, Z.; Wu, Y.; Chen, Q.; Li, X.; Jie, X.; Li, L.; Yao, M.; Guo, X.; et al. Rapid Flu Diagnosis Using Silicon Nanowire Sensor. Nano Lett. 2012, 12, 3722-3730. [CrossRef]

30. Kao, C.H.; Chen, H.; Huang, C.-Y. Effects of Ti addition and annealing on high-k Gd2O3 sensing membranes on polycrystalline silicon for extended-gate field-effect transistor applications. Appl. Surf. Sci. 2013, 286, 328-333. [CrossRef]

31. Bunjongpru, W.; Sungthong, A.; Porntheeraphat, S.; Rayanasukha, Y.; Pankiew, A.; Jeamsaksiri, W.; Srisuwan, A.; Chaisriratanakul, W.; Chaowicharat, E.; Klunngien, N.; et al. Very low drift and high sensitivity of nanocrystal-TiO2 sensing membrane on pH-ISFET fabricated by CMOS compatible process. Appl. Surf. Sci. 2013, 267, 206-211. [CrossRef]

32. Khanna, V.K.; Oelßner, W.; Guth, U. Interfacial and adhesional aspects in polyurethane (PUR) membrane coating on Si3N4 surface of ISFET gate for REFET fabrication. Appl. Surf. Sci. 2009, 255, 7798-7804. [CrossRef]

33. Ahn, J.-H.; Choi, S.-J.; Han, J.-W.; Park, T.J.; Lee, S.Y.; Choi, Y.-K. Double-Gate Nanowire Field Effect Transistor for a Biosensor. Nano Lett. 2010, 10, 2934-2938. [CrossRef] [PubMed]

34. Patolsky, F.; Zheng, G.; Hayden, O.; Lakadamyali, M.; Zhuang, X.; Lieber, C.M. Electrical detection of single viruses. Proc. Natl. Acad. Sci. USA 2004, 101, 14017-14022. [CrossRef] [PubMed]

35. Kao, L.T.-H.; Shankar, L.; Kang, T.G.; Zhang, G.; Tay, G.K.I.; Rafei, S.R.M.; Lee, C.W.H. Multiplexed detection and differentiation of the DNA strains for influenza A (H1N1 2009) using a silicon-based microfluidic system. Biosens. Bioelectron. 2011, 26, 2006-2011. [CrossRef] [PubMed]

36. Lin, C.-H.; Hung, C.-H.; Hsiao, C.-Y.; Lin, H.-C.; Ko, F.-H.; Yang, Y.-S. Poly-silicon nanowire field-effect transistor for ultrasensitive and label-free detection of pathogenic avian influenza DNA. Biosens. Bioelectron. 2009, 24, 3019-3024. [CrossRef] 
37. Gao, A.; Lu, N.; Dai, P.; Li, T.; Pei, H.; Gao, X.; Gong, Y.; Wang, Y.; Fan, C. Silicon-Nanowire-Based CMOS-Compatible Field-Effect Transistor Nanosensors for Ultrasensitive Electrical Detection of Nucleic Acids. Nano Lett. 2011, 11, 3974-3978. [CrossRef]

38. Takeda, S.; Sbagyo, A.; Sakoda, Y.; Ishii, A.; Sawamura, M.; Sueoka, K.; Kida, H.; Mukasa, K.; Matsumoto, K. Application of carbon nanotubes for detecting anti-hemagglutinins based on antigen-antibody interaction. Biosens. Bioelectron. 2005, 21, 201-205. [CrossRef]

39. Bhattacharya, M.; Hong, S.; Lee, D.; Cui, T.; Goyal, S.M. Carbon nanotube based sensors for the detection of viruses. Sensors Actuators B Chem. 2011, 155, 67-74. [CrossRef]

40. Tam, P.D.; Van Hieu, N.; Chien, N.D.; Le, A.-T.; Anh Tuan, M. DNA sensor development based on multi-wall carbon nanotubes for label-free influenza virus (type A) detection. J. Immunol. Methods 2009, 350, 118-124. [CrossRef]

41. Hideshima, S.; Hinou, H.; Ebihara, D.; Sato, R.; Kuroiwa, S.; Nakanishi, T.; Nishimura, S.-I.; Osaka, T. Attomolar Detection of Influenza A Virus Hemagglutinin Human H1 and Avian H5 Using Glycan-Blotted Field Effect Transistor Biosensor. Anal. Chem. 2013, 85, 5641-5644. [CrossRef]

42. Cho, H.; Kim, K.; Yoon, J.-S.; Rim, T.; Meyyappan, M.; Baek, C.-K. Optimization of Signal to Noise Ratio in Silicon Nanowire ISFET Sensors. IEEE Sens. J. 2017, 17, 2792-2796. [CrossRef]

(C) 2019 by the authors. Licensee MDPI, Basel, Switzerland. This article is an open access article distributed under the terms and conditions of the Creative Commons Attribution (CC BY) license (http://creativecommons.org/licenses/by/4.0/). 